\title{
Possibilities of Creating a Mechanism on FDM 3D Printer
}

Jan Strnad, Martin Reznicek, Kristyna Jelinkova, Janostik Vaclav, Martin Ovsik

Tomas Bata University in Zlin, TGM 5555, 76001 Zlin, Czech Republic. E-mail: mreznicek@utb.cz

\begin{abstract}
The article deals with additive manufacturing technologies especially with ability to create reports on FDM 3D printers. These assemblies are non-disambiguable. Therefore, it is important to choose the optimal magnitude of the deviation between the walls so that the mechanism has the required mobility. These deviations are examined in several materials with different rheological properties. Finally, the dependence of the magnitude of the variance between the walls and the thickness of the layer for the given materials is shown. The result is the recommendation of modelling and printing parameters.
\end{abstract}

Keywords: FDM, 3D print, deviation, model, parameters

\section{Introduction}

This article deals with the method FDM (fusion deposition model). This method is one of the most often used type of component production esoecially for its low purchase costs for the machine and the material. As semifinished products for melt deposition are used fibers of polymeric material. The 3D model is produced by extruding the material on the printing bed where the individual layers of polymeric material are layered on top of one another .

Thank to this technology it is possible to quickly formed physical model of the part and designing the model is created using CAD software. 3D printing is very suitable for rapid prototyping because the production of individual samples is much less time-consuming and financially demanding then e.g. injection technology.

In the production of complex components has always been true that more complicated mart means more expensive production. For injection technology the complexity of the component has a significant impact on mold design that makes prototype production considerably more expensive than $3 \mathrm{D}$ printing. 3D printer "does not care" how simple or complex the part is, $3 \mathrm{D}$ print registers only how much material it consumes not how many details the design contains.

Nowadays, 3D printing is expanding mainly for companies that desire to extend their offer, improve current products and services, or create the new ones. New technologies influent reality especially when they are applied in everyday life. The most widespread is $3 \mathrm{D}$ print in the automotive industry where this technology dominates. [14]

This technology have got a lot of technological aspects that affect the accuracy of production. The accuracy of joints is influenced by many factors. In order to make the joint or the mechanism as accurate as possible we have to consider several aspects. One of the most important is the correct calibration of the printing bed. Another, very significant effect can have a material shrinkage which influences the shape and dimensional accuracy of the printed model.

The shrinking size may be minimized if we choose the right machine, set well the production process and product material. In addition to that, the printing bed should have a constant temperature across the surface. Unfortunately, the highest temperature is in the middle of the bed. When we print closer to the edge the temperature decreases.

The design of the printer has a strong impact on the amount of shrinkage. Two different types of 3D printer can be distinguished; printer with close or open workspace.

The closed workspace printers with covers are better maintained and prevent larger temperature fluctuations due to the effects of the environment. The composition of the partially crystalline thermoplastic material has higher shrinkage values than amorphous thermoplastics.

The size of the printed object also influences the shrinkage. A larger shrinking occurs for larger volume models. Furthermore, when the model covers most of the printing bed it does not have to fit perfectly on it and it unsticks. [5-8]

\section{Methods}

\subsection{Test sample}

A ball joint was selected for evaluation (Fig. 1). This connection is non-disambiguable. Due to its design it contains a wide range of angles where inaccuracies can occur.

The test sample is in the shape of cube with the edge of $16 \mathrm{~mm}$ lenght and the spherical diameter of ball joint is $10 \mathrm{~mm}$.

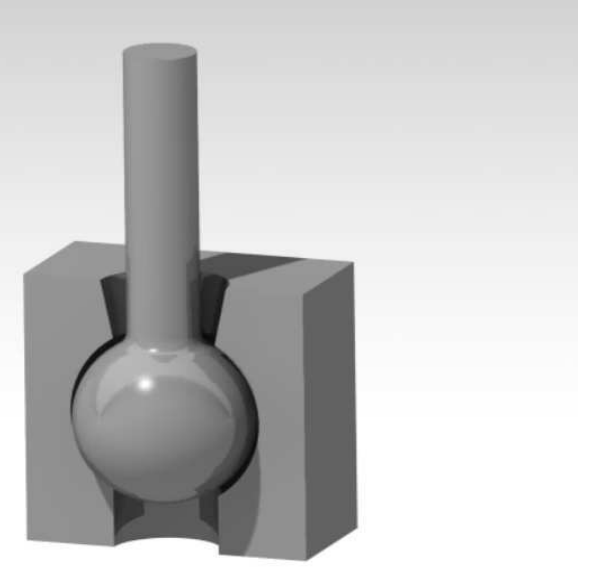

Fig. 1 Test sample - ball joint 
The print of these joints was carried out on several materials: Z-Ultrat, Z-HIPS and Timberfill. Material ZUltrat, Z-HIPS are original materials recommended by the producer while Timberfill material is from another production.

Each of these materials has different physical and mechanical properties.

Test sample was designed in 3D software Catia V5 and the setting of printing parameters was performed in Z-Suite software.

\subsection{Materials used for 3D printing}

\section{Z-Ultrat}

This is the original material recommended by the producer. It is an acrylonitrile butadiene styrene (ABS) material with a few percent of polycarbonate (PC). For its high hardness, low elasticity and low deformation Z-Ultrat is recommended for structural parts and mechanically stressed parts.

\section{Tab. 1 Z-Ultrat material parameters}

\begin{tabular}{|c|c|c|c|}
\hline $\begin{array}{c}\text { Material den- } \\
\text { sity }\end{array}$ & $\begin{array}{c}\text { Extruder tem- } \\
\text { perature }\end{array}$ & $\begin{array}{c}\text { Bed tempera- } \\
\text { ture }\end{array}$ & $\begin{array}{c}\text { Printing } \\
\text { speed }\end{array}$ \\
\hline $1080 \mathrm{~kg} / \mathrm{m}^{3}$ & $255-270^{\circ} \mathrm{C}$ & $80-110^{\circ} \mathrm{C}$ & $30 \mathrm{~mm} / \mathrm{s}$ \\
\hline
\end{tabular}

\section{Z-Hips}

High impact polystyrene (HIPS) is high-density polystyrene from the same producer as Z-Ultrat. This thermoplastic polystyrene has a rubber addition. As its name would suggest, the material is very tough, solid and has good temperature stability. HIPS is a good machinable material moreover it has far less thermal shrinkage in comparison to ABS.

\section{Tab. 2 HIPS material parameters}

\begin{tabular}{|c|c|c|c|}
\hline $\begin{array}{c}\text { Material den- } \\
\text { sity }\end{array}$ & $\begin{array}{c}\text { Extruder tem- } \\
\text { perature }\end{array}$ & $\begin{array}{c}\text { Bed tempera- } \\
\text { ture }\end{array}$ & $\begin{array}{c}\text { Printing } \\
\text { speed }\end{array}$ \\
\hline $1040 \mathrm{~kg} / \mathrm{m}^{3}$ & $220-240^{\circ} \mathrm{C}$ & $100-120^{\circ} \mathrm{C}$ & $30 \mathrm{~mm} / \mathrm{s}$ \\
\hline
\end{tabular}

\section{Timberfill}

This is the only non-original material from another producer. It imitates wood material. The fiber is a mixture of recycled wood with a polylactic acid based binding polymer. The color of objects is dependent on the print temperature. The higher the temperature means the darker shade of the material.

Tab. 3 Timberfill material parameters
\begin{tabular}{|c|c|c|c|}
\hline $\begin{array}{c}\text { Material den- } \\
\text { sity }\end{array}$ & $\begin{array}{c}\text { Extruder tem- } \\
\text { perature }\end{array}$ & $\begin{array}{c}\text { Bed tempera- } \\
\text { ture }\end{array}$ & $\begin{array}{c}\text { Printing } \\
\text { speed }\end{array}$ \\
\hline $1280 \mathrm{~kg} / \mathrm{m}^{3}$ & $170-185^{\circ} \mathrm{C}$ & $40-50{ }^{\circ} \mathrm{C}$ & $20-30 \mathrm{~mm} / \mathrm{s}$ \\
\hline
\end{tabular}

\subsection{Production of test samples}

Test samples are created on 3D printer Zortrax m200. This $3 \mathrm{D}$ printer has stable and tough construction and it is one of the most precise desktop 3D printers.

In Tab. 4 and 6 are showed parameters of 3D printing, followed by temperature settings in Tab. 5 .

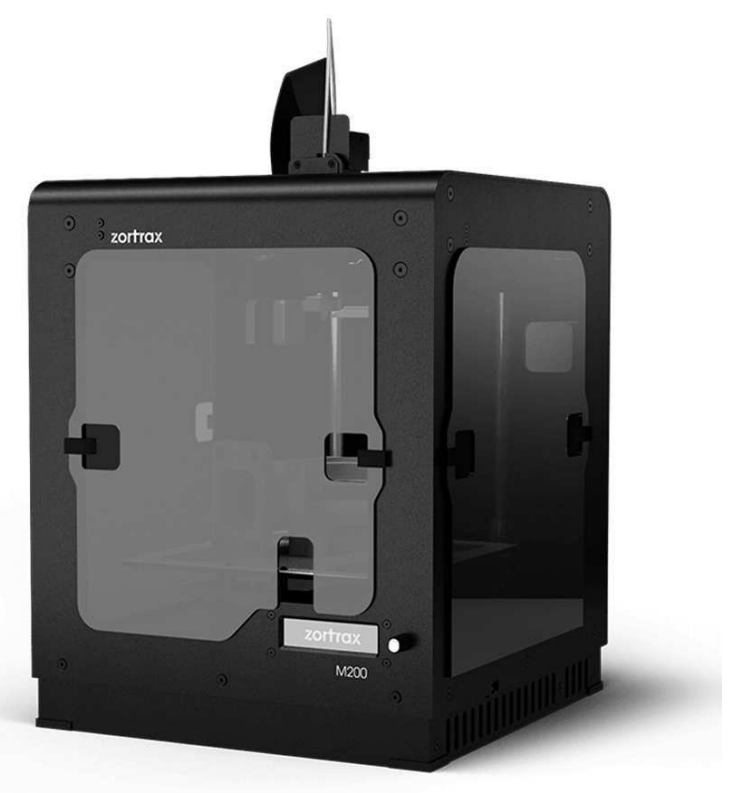

Fig. 23 p printer Zortrax $m 200$

Tab. 4 Printing parameters

\begin{tabular}{|l|l|}
\hline Technology & $\begin{array}{l}\text { LPD (Layer Plastic Deposi- } \\
\text { tion) }\end{array}$ \\
\hline Layer resolution & $90-390$ microns \\
\hline $\begin{array}{l}\text { Minimal wall thic- } \\
\text { kness }\end{array}$ & 400 microns \\
\hline Platform levelling & $\begin{array}{l}\text { Automatic platform points } \\
\text { height measurement }\end{array}$ \\
\hline
\end{tabular}

Tab 5. Temperatures of printing

\begin{tabular}{|l|l|}
\hline $\begin{array}{l}\text { Maximum printing temperature (ex- } \\
\text { truder) }\end{array}$ & $\mathbf{2 9 0}{ }^{\circ} \mathbf{C}$ \\
\hline Build platform & Heated \\
\hline Maximum platform temperature & $105^{\circ} \mathrm{C}$ \\
\hline Ambient operation temperature & $20-30^{\circ} \mathrm{C}$ \\
\hline Storage temperature & $0-35^{\circ} \mathrm{C}$ \\
\hline
\end{tabular}

Tab. 63 D printer parameters

\begin{tabular}{|l|l|}
\hline Build volume & $\mathbf{2 0 0} \mathbf{2 0 0} \mathbf{~ 1 8 0} \mathbf{~ m m}$ \\
\hline Material diameter & $1.75 \mathrm{~mm}$ \\
\hline Nozzle diameter & $0.4 \mathrm{~mm}$ \\
\hline Support & $\begin{array}{l}\text { Mechanically removed - prin- } \\
\text { ted from the same material as } \\
\text { the model }\end{array}$ \\
\hline Materials & $\begin{array}{l}\text { M Series dedicated materials } \\
\text { (recommended) }\end{array}$ \\
\hline External materials & Applicable \\
\hline
\end{tabular}

\subsection{The distance between adjacent walls}

This distance is important in terms of printing mechanical components. These components independently move and are non-detachable after they are removed from the workspace area of the 3D printer and after the removal of the support material, if appropriate. In the case of the FDM method it could happen that during the nozzle moving the fibres of the material are drawn between the individual walls. This causes that these walls are connected together and they cannot move by independently to the other. 
The ball joints were created with different distances between the walls: $0.2 ; 0.25 ; 0.30 ; 0.35 ; 0.40 ; 0.45 ; 0.50$; 0.55 and $0.60 \mathrm{~mm}$. Each joint is printed with different height of layer of the applied material. The heights were $0.09 ; 0.14 ; 0.19$ and $0.29 \mathrm{~mm}$.

For correct evaluation these samples were printed several times to make the repeatability more accurate and to confirm the accuracy of the results. The printing of samples in the extreme positions of the printing plate was another verification. Inaccurate calibration of the printer could cause the greater inaccuracies.

\section{Results and discussion}

From the printed samples of Z-Ultrat was found that the possibilities of forming mechanisms or non-disconnectable connections are possible from the smallest distance between the walls of $0.25 \mathrm{~mm}$. Layer height of $0.09 \mathrm{~mm}$ is required for this deviation. The optimal deviation values for this layer are $0.25 ; 0.30$ and $0.35 \mathrm{~mm}$.

The functional deviation for a layer height of $0.14 \mathrm{~mm}$ starts at $0.30 \mathrm{~mm}$. The recommended values for this layer are the deviation values are in range from 0.30 to 0.40 $\mathrm{mm}$. The 0.09 and $0.14 \mathrm{~mm}$ layers achieved the best results from the three studied materials. Modelling deviations are the smallest.

The recommended values of modelling deviations for layer height of $0.19 \mathrm{~mm}$ are $0.40 ; 0.45 ; 0.50 \mathrm{~mm}$. The accuracy was lower for the thickest layer height of $0.29 \mathrm{~mm}$. The deviation performing the required range of movements starts from $0.55 \mathrm{~mm}$.

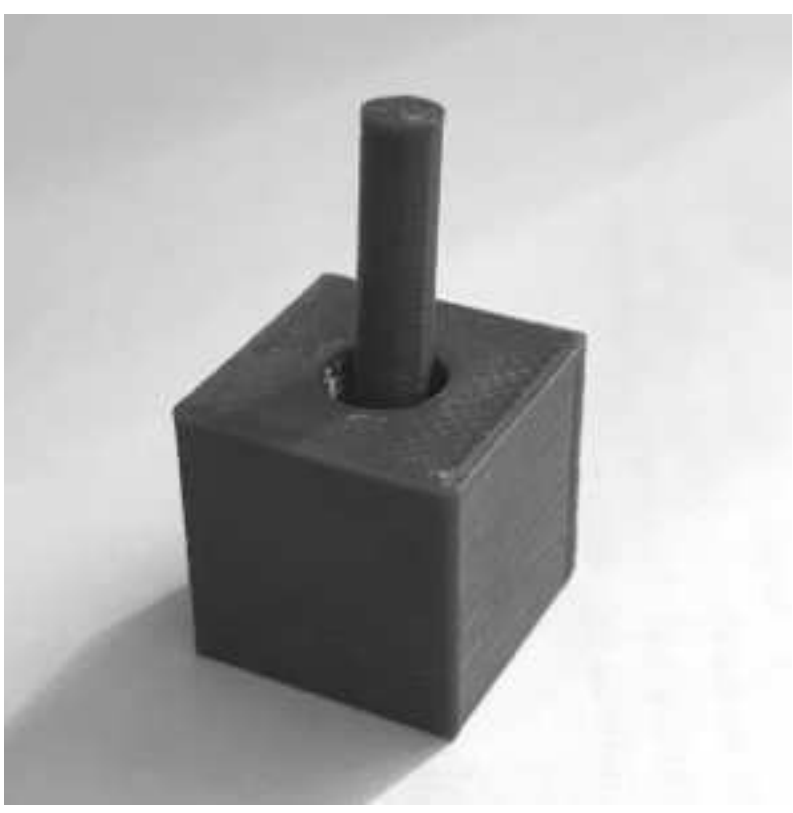

Fig. 3 Test Sample of material Z-Ultrat

Tab. 9 Results of Z-Ultrat material; layer height and deviation is given in $\mathrm{mm}$; $X$-limited mobility or complete connection, OK - suitable modeling deviation, $\uparrow$ - inappropriate range of moving, unwanted linear movement in all directions

\begin{tabular}{|l|l|l|l|l|l|l|l|l|}
\hline Z-Ultrat & \multicolumn{10}{|l|}{$\mid$} \\
\hline Layer height/ deviation & 0.20 & 0.25 & 0.30 & 0.35 & 0.40 & 0.45 & 0.50 & 0.55 \\
\hline 0.09 & $\mathrm{X}$ & $\mathrm{OK}$ & $\mathrm{OK}$ & $\mathrm{OK}$ & $\uparrow$ & $\uparrow$ & $\uparrow$ & $\uparrow$ \\
\hline 0.14 & $\mathrm{X}$ & $\mathrm{X}$ & $\mathrm{OK}$ & $\mathrm{OK}$ & $\mathrm{OK}$ & $\uparrow$ & $\uparrow$ & $\uparrow$ \\
\hline 0.19 & $\mathrm{X}$ & $\mathrm{X}$ & $\mathrm{X}$ & $\mathrm{X}$ & OK & OK & OK & $\uparrow$ \\
\hline 0.29 & $\mathrm{X}$ & $\mathrm{X}$ & $\mathrm{X}$ & $\mathrm{X}$ & $\mathrm{X}$ & $\mathrm{X}$ & $\mathrm{X}$ & $\mathrm{OK}$ \\
\hline
\end{tabular}

Another explored material was HIPS. For this material was found that the possibilities of forming mechanisms or non-disambiguable joints are real from the smallest distance between the walls of $0.35 \mathrm{~mm}$. For this size of deviation it is necessary to set a layer height of 0.09 and $0.14 \mathrm{~m}$. The optimum deviation values for these layers are $0.35 ; 0.40$ and $0.45 \mathrm{~mm}$.

For a layer height of $0.19 \mathrm{~mm}$ the functional deviation is at the lowest value of $0.40 \mathrm{~mm}$. The recommended values of deviation for this layer are in range from 0.40 to $0.50 \mathrm{~mm}$.

At the biggest layer height of $0.29 \mathrm{~mm}$ the accuracy was lower. The size of the deviation performing required movement starts from $0.50 \mathrm{~mm}$. Thus, a suitable setting for a $0.29 \mathrm{~mm}$ layer height is the deviation of $0.50 ; 0.55$ and $0.60 \mathrm{~mm}$.

HIPS material is more suitable for larger dimensional mechanisms. It does not shrink as much as ABS and the others ABS-base materials.

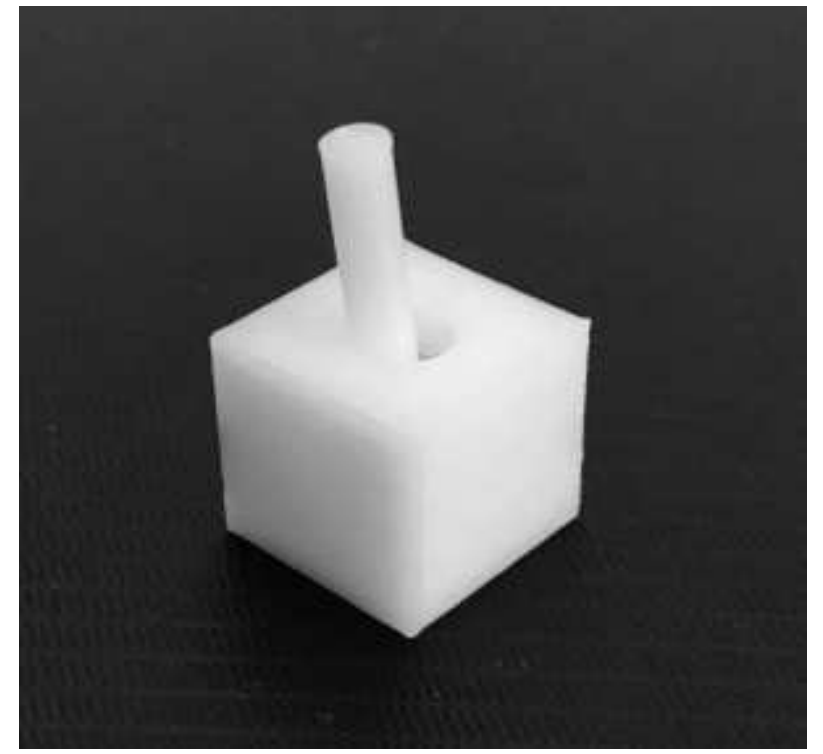

Fig. 4 Test Sample of material Z-Hips 
Tab. 7 Results of HIPS material; layer height and deviation is given in mm; $X$-limited mobility or complete connection, OK - suitable modeling deviation, $\uparrow$ - inappropriate range of moving, unwanted linear movement in all directions

\begin{tabular}{|l|l|l|l|l|l|l|l|l|}
\hline Z-HIPS & 0.30 & 0.35 & 0.40 & 0.45 & 0.50 & 0.55 & 0.60 & 0.65 \\
\hline $\begin{array}{l}\text { Layer height/ } \\
\text { deviation }\end{array}$ & $\mathrm{X}$ & $\mathrm{OK}$ & $\mathrm{OK}$ & $\mathrm{OK}$ & $\uparrow$ & $\uparrow$ & $\uparrow$ & $\uparrow$ \\
\hline 0.09 & $\mathrm{X}$ & $\mathrm{OK}$ & $\mathrm{OK}$ & $\mathrm{OK}$ & $\uparrow$ & $\uparrow$ & $\uparrow$ & $\uparrow$ \\
\hline 0.14 & $\mathrm{X}$ & $\mathrm{X}$ & $\mathrm{OK}$ & $\mathrm{OK}$ & $\mathrm{OK}$ & $\uparrow$ & $\uparrow$ & $\uparrow$ \\
\hline 0.19 & $\mathrm{X}$ & $\mathrm{X}$ & $\mathrm{X}$ & $\mathrm{X}$ & $\mathrm{OK}$ & $\mathrm{OK}$ & $\mathrm{OK}$ & $\uparrow$ \\
\hline 0.29 & & & & & \\
\hline
\end{tabular}

The last studied material is Timberfill. From the printed samples it was found that the possibilities of forming mechanisms or indivisible joints are conceivable from the smallest distances between the walls of $0.30 \mathrm{~mm}$. For this size of distance a layer height of $0.09 \mathrm{~mm}$ has to be set. For this layer the recommended values of deviation are $0.30 ; 0.35$ and $0.40 \mathrm{~mm}$. For layer height of $0.14 \mathrm{~mm}$ the connection works at a size of $0.35 ; 0.40$ and $0.45 \mathrm{~mm}$.

At a layer height of $0.19 \mathrm{~mm}$ a minimum deviation of $0.40 \mathrm{~mm}$ was achieved. Recommended values for this layer are in range from 0.40 to $0.50 \mathrm{~mm}$.

At the thickest layer height of $0.29 \mathrm{~mm}$ the accuracy was considerably lower. The size of deviation required for movement began from $0.60 \mathrm{~mm}$. Therefore, a suitable setting for a $0.29 \mathrm{~mm}$ layer height is the deviation value $0.60 \mathrm{~mm}$ and higher.

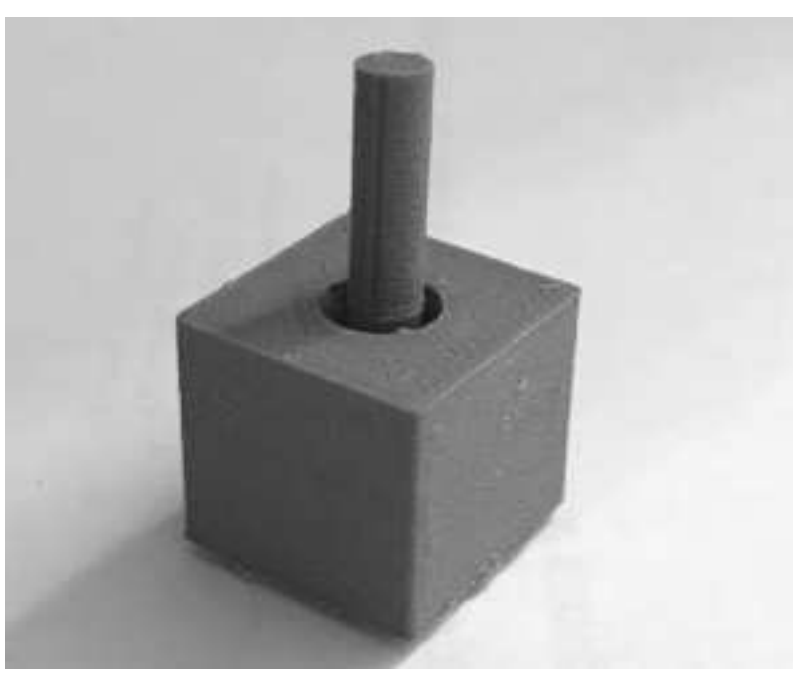

Fig. 5 Test Sample of material Timberfill

Tab. 8 Results of Timberfill material; layer height and deviation is given in mm; $X$ - limited mobility or complete connection, OK - suitable modeling deviation, $\uparrow$ - inappropriate range of moving, unwanted linear movement in all directions Timberfill

\begin{tabular}{|l|l|l|l|l|l|l|l|l|}
\hline Layer height/ deviation & 0.25 & 0.30 & 0.35 & 0.40 & 0.45 & 0.50 & 0.55 & 0.60 \\
\hline 0.09 & $\mathrm{X}$ & $\mathrm{OK}$ & $\mathrm{OK}$ & $\mathrm{OK}$ & $\uparrow$ & $\uparrow$ & $\uparrow$ & $\uparrow$ \\
\hline 0.14 & $\mathrm{X}$ & $\mathrm{X}$ & $\mathrm{OK}$ & $\mathrm{OK}$ & $\mathrm{OK}$ & $\uparrow$ & $\uparrow$ & $\uparrow$ \\
\hline 0.19 & $\mathrm{X}$ & $\mathrm{X}$ & $\mathrm{X}$ & $\mathrm{OK}$ & $\mathrm{OK}$ & $\mathrm{OK}$ & $\uparrow$ & $\uparrow$ \\
\hline 0.29 & $\mathrm{X}$ & $\mathrm{X}$ & $\mathrm{X}$ & $\mathrm{X}$ & $\mathrm{X}$ & $\mathrm{X}$ & $\mathrm{X}$ & $\mathrm{OK}$ \\
\hline
\end{tabular}

\section{Conclusion}

The test samples were designed and produced according to the recommended process conditions specified by the producer of the used materials. The printing ran in the closed area of the printer with covers. The extrusion nozzle and the print bed have been properly cleaned. The bed was calibrated to the plane.

For the thinnest $0.09 \mathrm{~mm}$ layer, Z-Ultrat has the best results with a designed deviation of $0.25 \mathrm{~mm}$. Timberfil matched the desired range of motion with a wall distance of $0.30 \mathrm{~mm}$. Samples of HIPS material with desired properties start at $0.35 \mathrm{~mm}$ of layer height. This material is suitable for use on mechanisms with larger dimensions due to its shrinking values.

The most optimal choice of layer in the forming of mechanisms or individual joints is a layer height of 0.09 and $0.14 \mathrm{~mm}$ where all materials achieve the highest precision. With a higher layer of the applied material the joints are more prone to breakage.
Values of distances between the walls (deviations) that are lower than the recommended deviations are inconvenient and the full range of motion is unable. In most cases the opposed walls will be completely joined together.

Higher than recommended values cause inappropriate range of motion. They cause undesirable short, linear movement in all directions.

\section{Acknowledgement}

This work and the project is realized with the financial support of the internal grant of $T B U$ in Zlin No. IGA/FT/2019/001 funded from the resources of specific university research. 


\section{References}

[1] GIBSON, I., ROSEN, D.; STUCKER, B. (2015). Additive Manufacturing Technologies: 3D Printing, Rapid Prototyping, and Direct Digital Manufacturing. 2015.

[2] BERMAN, B. (2012). 3-D printing. Business Horizons [online]. Elsevier, 2012, 55(2), 155-162 [cit. 2017-12-02]. DOI: 10.1016/j.bushor.2011.11.003. ISSN 00076813.

[3] ŠAFKA, J., ACKERMANN, M., BOBEK, J., SEIDL, M., HABR, J. BĚHÁLEK, L. (2016). Use of composite materials for FDM 3D print technology. Materials Science Forum [online]. Trans Tech Publications, 2016, 862, 174-181 [cit. 201802-23]. DOI: $10.4028 /$ www.scientific.net/MSF.862.174. ISSN 02555476.

[4] STANEK, M.; MANAS, M.; MANAS, D.; KYAS, K.; PATA, V.; SENKERIK, V. (2011). Rapid Prototyping the Fast Tool for Model Production. Annals of DAAAM and Proceedings of the International DAAAM Symposium. 2011, s. 157158. ISSN:1726-9679.
[5] LUAN, He a Qiang HUANG. (2015). Predictive modeling of in-plane geometric deviation for $3 \mathrm{D}$ printed freeform products. 2015 IEEE International Conference on Automation Science and Engineering (CASE) [online]. IEEE, 2015, , 912-917 [cit. 2018-02-23]. DOI: 10.1109/CoASE.2015.7294215.

[6] MULLER, M. (2017). Effects of Aluminium Microparticles and Surface Treatment of $\mathrm{AlCu} 4 \mathrm{Mg}$ on Mechanical Properties of Adhesive Bond Strength. In: Manufacturing Technology, Vol. 17, pp. 66-71.

[7] OVSIK, M., STANEK, M., HYLOVA, L., MANAS, M., STOKLASEK, P. (2019). The thermal energy influence on the surface layer of construction steels during laser beam cutting (2019) Manufacturing Technology, 19 (1), pp. 123-128.

[8] STANEK, M., M. MANAS, M. OVSIK, M. REZNICEK, V. SENKERIK, AND V. JANOSTIK. (2019). "Polymer Flow Influenced by Mold Cavity Surface Roughness." Manufacturing Technology 19 (2): 327-331. 